\title{
Effect of Sodium Chloride on Properties of Bitumen
}

\author{
Md. Shariful Islam \\ Department of Civil Engineering, RUET, Bangladesh
}

\begin{abstract}
Now-a-days a lot of modifications are taking place throughout the world to develop the existing highway materials to fulfill the demand of increased vehicles. People are at trend to innovate something new that can do better than it was. Some materials produce good effect and enhance the strength as well as qualities of bitumen. On the other hand, some materials are responsible for adverse effect on the bitumen. In saline areas like coastal regions, the salts play a significant role on the bituminous pavements. Sea water nearly contains 3\% sodium chloride and evaporation of intake bodies of water has produced large and extensive deposits of it. We can be economically benefited if salt is used as an admixture to bitumen. But we do not even know the impact, good or bad of the mixing of salt with bitumen. The main objective of this paper to find out whether it is desirable or not taking various proportion salt with bitumen and doing specified test of bitumen. It is observed from the laboratory test that the penetration and ductility values are gradually increased with increased of salt content. The flash point, fire point and softening point value are stepwise reduced as percentage of salt content increased. Moreover it reduces the stability of roads. Mixing of salt to bitumen upgrades workability and it is beneficial in the economical point of view. Finally moisture effect test on the bituminous mix with the inclusion of salts show the degradation of strength due to moisture movement.
\end{abstract}

Key words: Sodium chloride, bitumen, bituminous mix, flash fire point, stability.

\section{Introduction}

Bituminous mixes are most commonly used all over the world in pavement construction. Under normal circumstances, conventional bituminous materials if designed and executed properly perform quite satisfactory. But for special applications like roundabouts or where the traffic is extremely heavy, stiffer mixes are required which can have large fatigue life and more resistance permanent deformation. Most publications ascribe moisture damage to variables like bitumen properties, aggregate characteristics, hot mix processing, bituminous mixture characteristics, quality control during construction, nature of water at the interface, dynamic effect of traffic loading, type and properties of anti stripping additives, and others. The great diversity of variables and differences in earlier research results reported make prediction of moisture sensitivity difficult. Most mechanistic design methods for bituminous pavements mainly base on fatigue and

Corresponding author: Md. Shariful Islam, B.Sc., research field: civil engineering. rutting as the primary design criteria. However, SHRP's mechanistic/analytical approach to pavement design proposed the need to consider resistance to moisture damage as a key factor in selection and proportioning of binders and aggregates [1-3].

In coastal area, pavement often comes across with saline water. In this area, the salts particularly sodium chloride plays an important role in the stability as well as durability of roads. In this situation, the effect of salts on properties of bitumen is important for proper design and maintenance of the pavements. The present status of literature, indicates that a little work has been conducted to determine the behavioral changes in the bituminous pavements in the present of salts. In this paper, an attempt has been undertaken to study the effect of salts on varies properties of bitumen.

\section{Objective of Study}

In recent years, a significant achievement has been made in different fields of engineering. Also various causes have been effectively determined to take appropriate measures against the determination and 
detrimental effect. In general, the presence alkalis and salts produce harmful effect on the behavioral aspects of binding materials. In this study, an attempt has been made to quantify the adverse effects in term of some specific standard tests. The objectives of this study are:

- To find the effect of salts on the properties of bitumen;

- To determine the variation of strength with the inclusion of salts;

- To observe the effect of water on the strength of bituminous mixes with inclusion of salts in bitumen;

- To carefully examine the use of salts in the bitumen in terms of various properties such as penetration, solubility, ductility etc.

\section{Tested on Bitumen}

To determine its behavior and its suitability a variety of tests have been specified by institutions like ASTM, I.S.I, Asphalt Institute, and B.S.I. The various tests of bitumen are as follows:

(1) Penetration Test

Penetration value test on bitumen is a measure of hardness or consistency of bituminous material. Penetration value is the vertical distance traversed or penetrated by the point of a standard needle into the bituminous material under specific conditions of load, time and temperature. This distance is measured in one tenth of a millimeter.

(2) Softening Point Test

The softening point of bitumen or tar is the temperature at which the substance attains particular degree of softening. As per IS: 334-1982, ASTM E28-67 or ASTM D36 or ASTM D6493-11, it is the temperature in ${ }^{\circ} \mathrm{C}$ at which a standard ball passes through a sample of bitumen in a mould and falls through a height of $2.5 \mathrm{~cm}$, when heated under water or glycerin at specified conditions of test.

(3) Flash and Fire Point Test

Flash and Fire point test is conducted on bitumen to know the safe mixing and application temperature values of particular bitumen grade.

The flash point of a material is the lowest temperature in which vapor of substance quickly catches fire in the form of flash under definite conditions of the test. So, at this point fire will not last longer, just a flash will appear for a fraction of second.

The fire point of a material is the lowest temperature at which material catches fire and burns under definite conditions of test. The presence of combustible materials in a bituminous material can be indicated by the fire point.

(4) Ductility Test

The flexible pavement construction where the bitumen binders are used, is of significant importance that binders from ductile thin film around the aggregates. This serves as a satisfactory binder in improving physical interlocking of the aggregates. The binder material which does not possess sufficient ductility would crack and thus provide previous pavement surface. It has been started by some agencies that the penetration and ductility properties go together, but depending upon the chemical composition and the type of crude source of the bitumen, sometimes it has been observed that the above statement is incorrect. It may hence be mentioned that the bitumen may satisfy the penetration value, but may fail to satisfy the ductility requirements. Bitumen paving engineer would however want that both test requirements be satisfied in field jobs. Penetration or ductility can not in any case replace each other. The ductility is expressed as the distance in centimeters to which a standard briquette of bitumen can be stretched before the thread cracks. The test is conducted at $27 \pm 0.5^{\circ} \mathrm{C}$ and a rate of pull of $50 \pm 2.5 \mathrm{~mm}$ per minute. The test has been standardized by the ISI.

(5) Specific Gravity Test

The density of a bituminous binder is a fundamental property frequently used as an aid in classifying the binders used in paving jobs. In most applications, the 


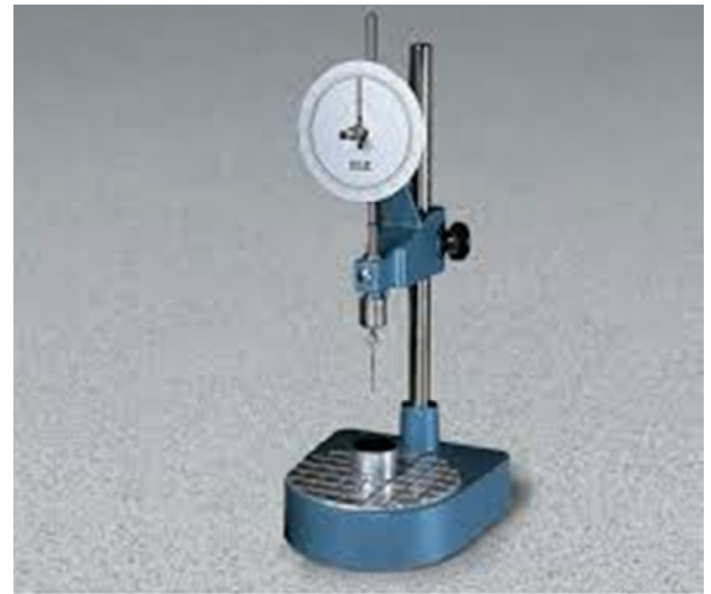

Fig. 1 Penetration test apparatus.

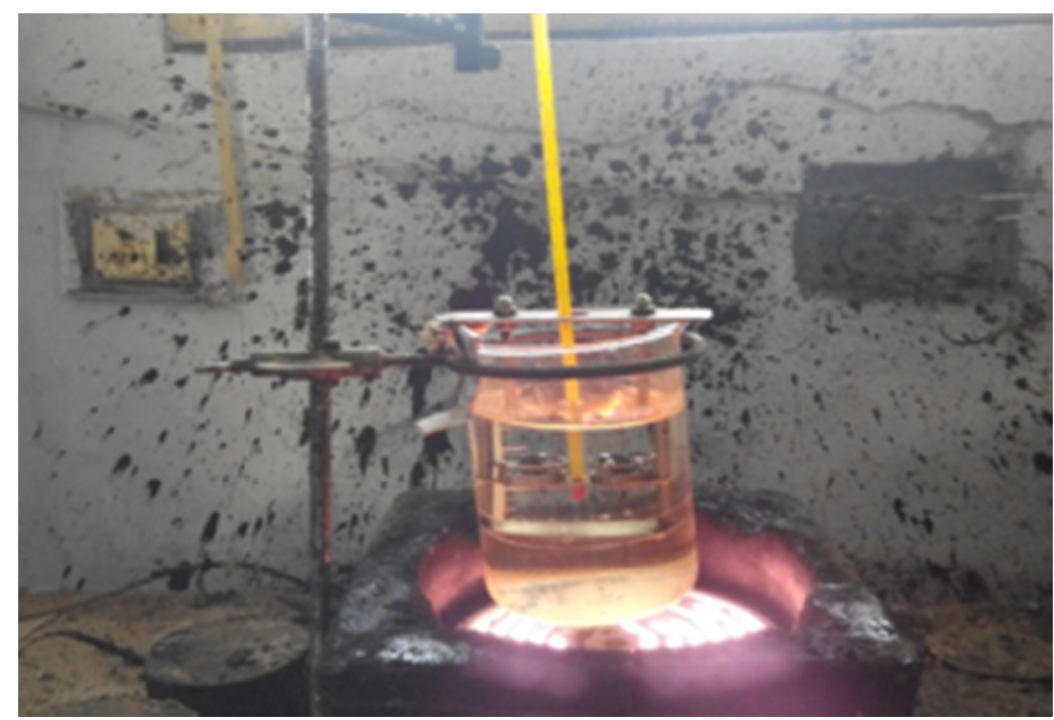

Fig. 2 Softening point test apparatus.

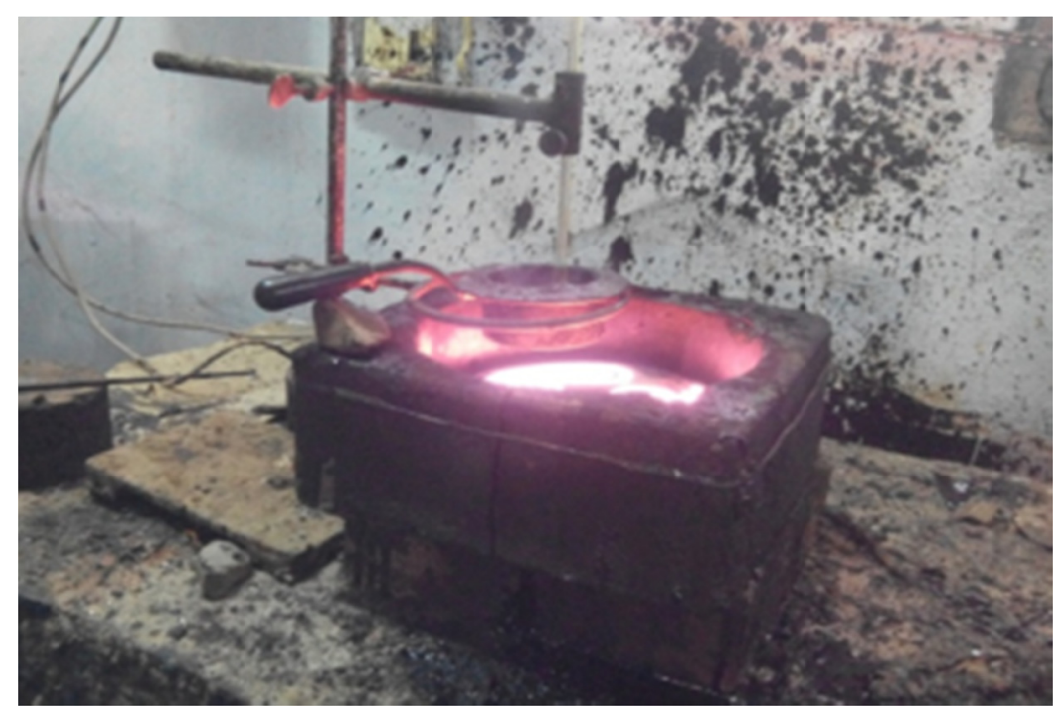

Fig. 3 Flash and fire point test. 


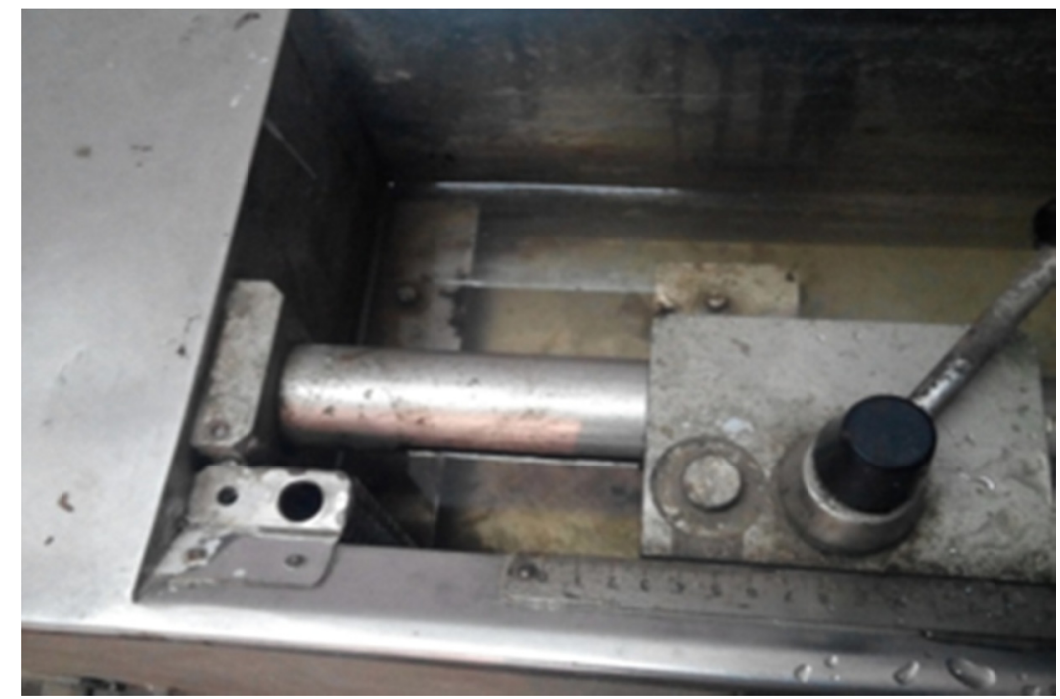

Fig. 4 Ductility test.

bitumen is weighted, but finally in use with aggregate system, the bitumen content is converted in volume basis. Thus an accurate density value is required for conversion of weight to volume. The specific gravity is greatly influenced by the chemical composition of the binder. Increased amounts of aromatic type compounds caused an increase in the specific gravity. The test procedure has been standardized by the ISI.

\section{Materials Used for Specimen}

(1) Bitumen

(2) Sodium chloride.

\subsection{Effect of Water on Bituminous Mixes}

One of the complex problems in the field of highway engineering, existing since bitumen paving technology came into existence is stripping. The term stripping, as employed by highway engineers, denotes the occurrence of adhesion failure or weakening of the cohesive bonds within the asphalt aggregate system. It is considered as great economic loss and engineering failure in terms of proper mixture design.

Majidzadeh stated that the factors affecting the adhesion failure phenomenon are innumerable. They include the material characteristics, construction techniques and diversified environmental conditions.
They are displacement, film rupture, detachment and pore pressure theories. Of course it is obvious that owing to the complexities of material composition and diversity of environmental conditions, no single mechanism may be adequate to explain the stripping phenomenon in bituminous mixtures. The concepts of the theories are briefly summarized as follows:

(1) Displacement Concept

According to this theory the binder aggregate function in the presence of water becomes thermodynamically unstable and reacts to more stable position [4-8]. It is generally believed that, in order to displace phenomena to be initiated in a mixture, the binder aggregate interface should become exposed to the water phase. That is well, coated aggregate may not exhibit any binder displacement unless the continuity of aggregate coating is destroyed.

(2) Detachment Concept

The theory attributes the adhesion to a thermodynamic replacement of the bitumen by a thin film of water that may come from either outside or from within the aggregate while from the bitumen coating remains intact [9-12]. The characteristics of the interface are believed to be very important in the detachment process. The water reaching the interface becomes intimately associated with the lattice of the mineral surface. 
(3) Pore Pressure Concept

It has been postulated that the buildup of pore pressure in the mixture of high void content may result in stripping phenomena [13]. That is, on a wet surface of bituminous pavement additional forces due to traffic also act and these greatly exceed the thermodynamic forces. In a saturated pavement under dynamic load, water is pressed into the pavement in front of the moving load and sucked out behind the wheel contributing to the stripping phenomena. Among these four concepts, the displacement and detachment theories can be classified as the primary causes of stripping and pore pressure, film rupture concepts in fact only contributing to the phenomena.

\subsection{Effect of Mixture Density on Stripping}

There are primarily three perquisites for the occurrence of stripping phenomena in bituminous mixtures: presence of water in pavement, repeated load application and the physiochemical nature of the bituminous aggregate system. In order to eliminate or reduce the chances of stripping, one should attempt at least one of these factors. From the pavement design point of view, the water present in the pavement can be reduced by decreasing the void content of the bituminous mixtures. In fact, this approach could be considered as one of the preventive measures in the construction of bituminous paving using the physio-chemically unstable bituminous aggregate system.

\subsection{Preparation of Compressive Strength Test Specimen}

The mix proportion of cement fine aggregate and coarse aggregate is 1:2:4. The water cement ratio is 0.50 . Test for compressive strength is carried out on cube. American Society for Testing Materials ASTM C39/C39M provides Standard Test. For cube test the types of specimen each cube $10 \mathrm{~cm} \times 10 \mathrm{~cm} \times 10 \mathrm{~cm}$ is used. After 24 hours these moulds are removed and test specimens are put in water for curing. The top surface of these specimens should be made even and smooth. These specimens are tested by compression testing machine after 3 days 7 days curing or 28 days curing. Load at the failure divided by area of specimen gives the compressive strength of concrete.

\subsection{Marshall Test Specimen}

The coarse aggregates, fine aggregates and mineral should be proportioned and mixed specified gradation of mineral aggregates and bitumen binder as per IRG.29-1968. Approximately 1,200 g of aggregates and filler are taken and heated to a temperature of $170{ }^{\circ} \mathrm{C}$ to $190{ }^{\circ} \mathrm{C}$. The compaction mould assembly, rammer, cleaned and kept pre-heated to temperature of $100{ }^{\circ} \mathrm{C}$ to $145{ }^{\circ} \mathrm{C}$. The mixing temperature for $80 / 100$ grade bitumen may be around $154{ }^{\circ} \mathrm{C}$ that for $60 / 70$ grade bitumen $160{ }^{\circ} \mathrm{C}$. The weight of aggregate taken may be suitably alerted a thickness of $63.5 \pm 3.0 \mathrm{~mm}$.

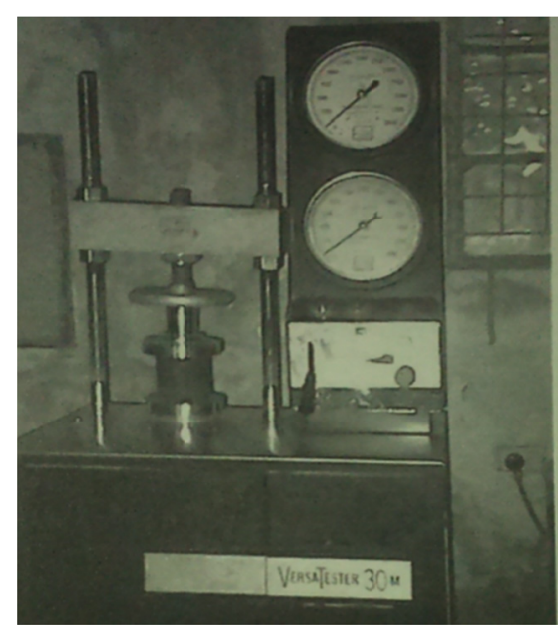

Fig. 5 Experimental setup of compressive strength. 


\section{Results and Discussions}

\subsection{Effect of Salt on Properties of Bitumen}

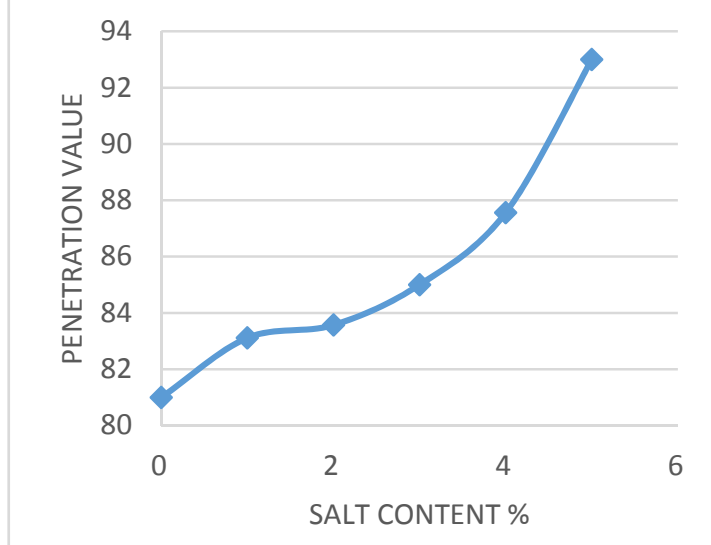

(a)

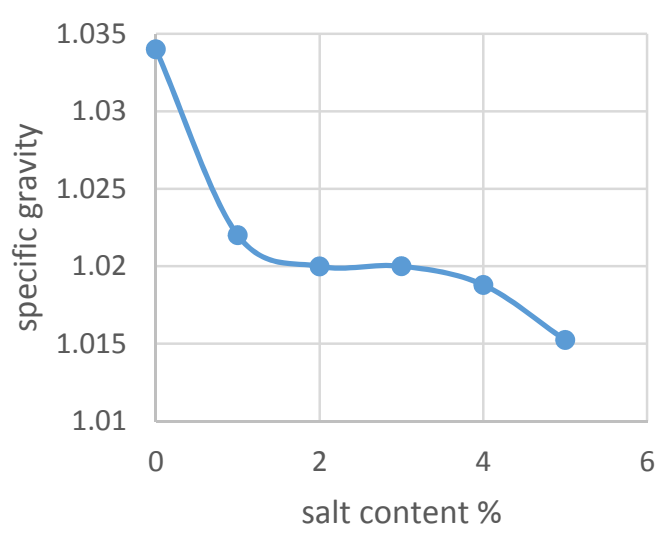

(b)

Fig. 6 (a) variation of penetration value and (b) specific gravity with respect to salt content.

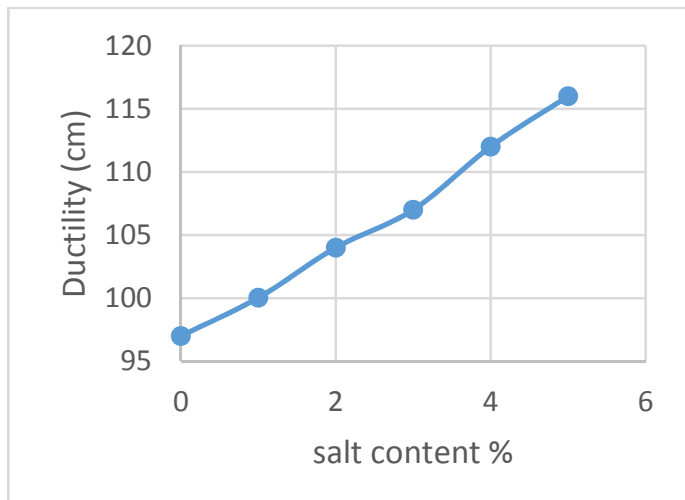

(c)

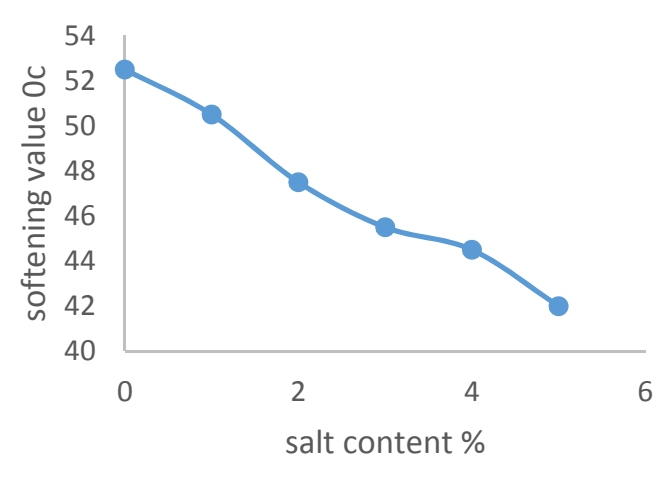

(d)

Fig. 7 (c) variation of ductility and (d) softening value with respect to salt content.

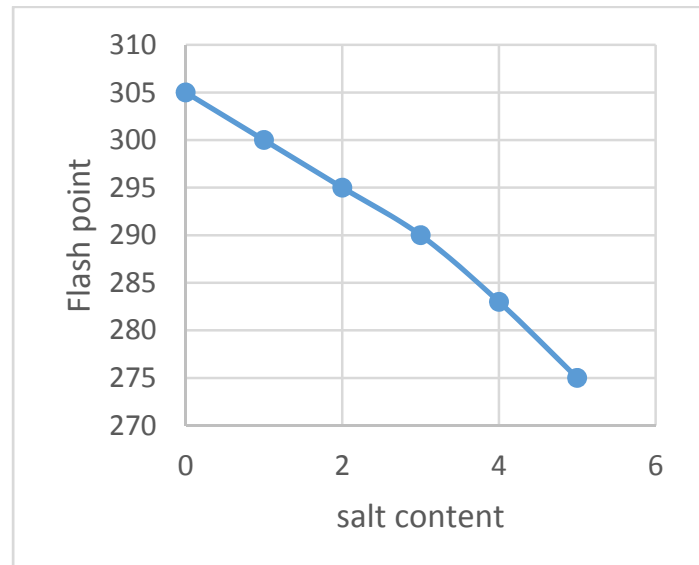

(e)

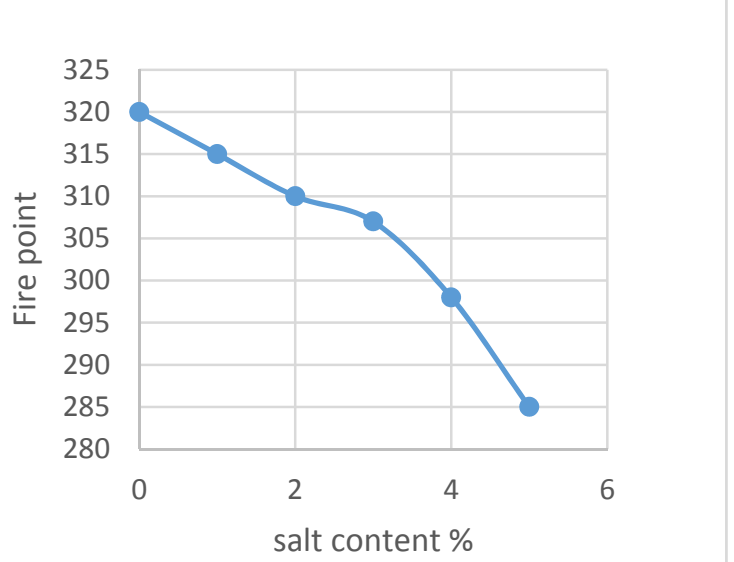

(f)

Fig. 8 (e) variation of flash point value and (f) fire point value with respect to salt content. 


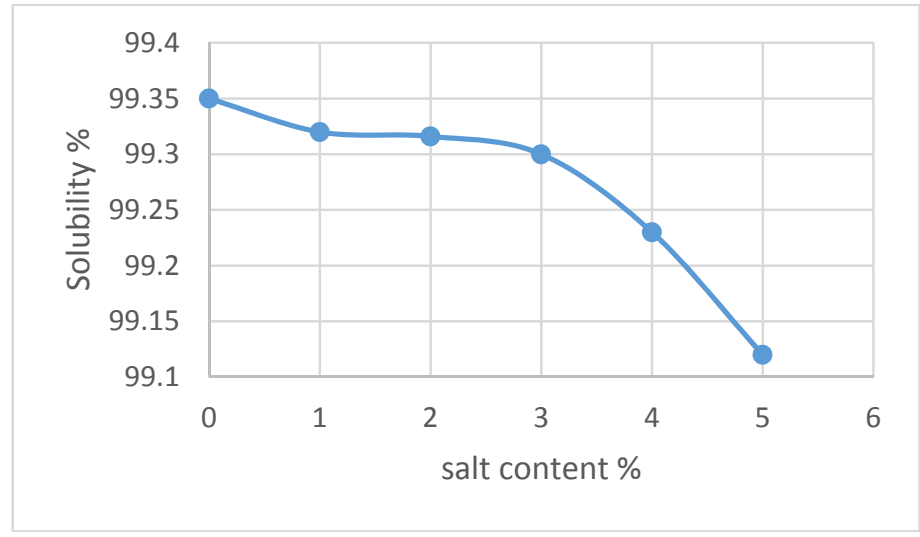

(g)

Fig. 9 (g) variation of solubility with respect to salt content.

\section{Conclusion}

Sodium chloride has played a crucial role in improvement of the different properties of the bitumen. But sometimes it has adverse effects as reducing the strength of the bituminous mixes. From the test results, we conclude that the stability value of the bituminous mixes decreases gradually with increase in salt content in bitumen. On the basis of the test results and subsequent discussions, it was concluded that the penetration value and specific gravity increases and softening point, flush \& fire point, solubility and ductility of bitumen decreases with increasing salt in pure bitumen which indicated that the adhesion and cohesion properties of bitumen were reduced with increasing the percentage of salt in bitumen.From the Marshall test regarding the consideration, the salt tolerable limit varying from $0 \%$ to $5 \%$.

\section{Acknowledgments}

Utmost gratitude to the Almighty ALLAH, without his mercy and blessing, this work would not been possible. I am grateful and would like to express sincere gratitude to my respective teachers, Department of Civil Engineering, Rashahi University of Engineering \& Technology, Rajshahi, for sharing their vision and experience that enabled me to successfully complete the work. I am also grateful to my parents and my friends, without their encouragement it is totally unable to complete this work.

\section{References}

[1] Alocoke, W. H. 1954. "An Investigation of Asphalt Paving Mixtures Containing Rubber Additives.” Masters diss., University of Kentucky.

[2] American Society for Testing and Materials (ASTM) D 2726, D 1074 D1075, C29 and C128. 1979.

[3] Afroz, S. S. K., and Prasad, K. S. B. 2012. "Utilization of Waste Plastic as a Strength Modifier in Surface Course of Flexible and Rigid Pavements." Int J Eng Res Appl 2 (4): 1185-91.

[4] Button, J. W., and Little, D. N. 1988. "Additives Have Potential to Improve Pavement Life." Scranton Gillette Communications, Roads and Bridges 26 (1): 76-80.

[5] Denning, J. H., and Carswell, J. 1981. Improvements in Rolled Asphalt Surfacing by Addition of Organic Polymers. Transport and Road Research Laboratory, United Kingdom.

[6] De Carteret, R. S., Buzzi, O., and Fityus, S. 2011. "A Review of the Effects of Salinity on Road Pavements and Bituminous Surfacings." Unsaturated Soils: Theory and Practice: 803-8.

[7] Prusty, B., and Panda, M. 2012. "Use of Waste Polythene in Bituminous Concrete Mixes." 108Ce036.

[8] Fromm, H. J., and Kennepohl, G. J. A. 1979. "Sulphur Asphaltic Concrete on Three Ontario Test Road." In Proc. of 48th Int. Conference on Association of Asphalt Paving Technologists, 135-62.

[9] Martin, J. R., and Wallace, H. A. 1958. Design and Construction of Asphalt Pavements. New York: McGraw Hill Book co.

[10] Soni, K., and Punjabi, K. K. 2014. "Improving the Performance of Bituminous Concrete Mix by Waste Plastic." Int. Journal of Engineering Research and Applications 3 (5): 863-8.

[11] Khanna, K. 1991. Highway Engineering (7th ed.). Delhi, 
India: Standard Publishers Distributors.

[12] Sangita, Tabrez Alam Khan, Sabin, R., and Sharma, D. K. 2010. "Effect of Waste Polymer Modifier on the Properties of Bituminous Concrete Mixes." Construction and Building Materials 25 (10): 3841-8.
[13] Yamin, A., and Aschuri, I. 2017. "The Durability Study of The Use of Modified Waste Plastic-Bitumen in Asphalt Concrete Mix Containing Reclaimed Asphalt Pavement." The Centre for Research and Development of Road and Bridge, Indonesia. 


\section{Appendix}

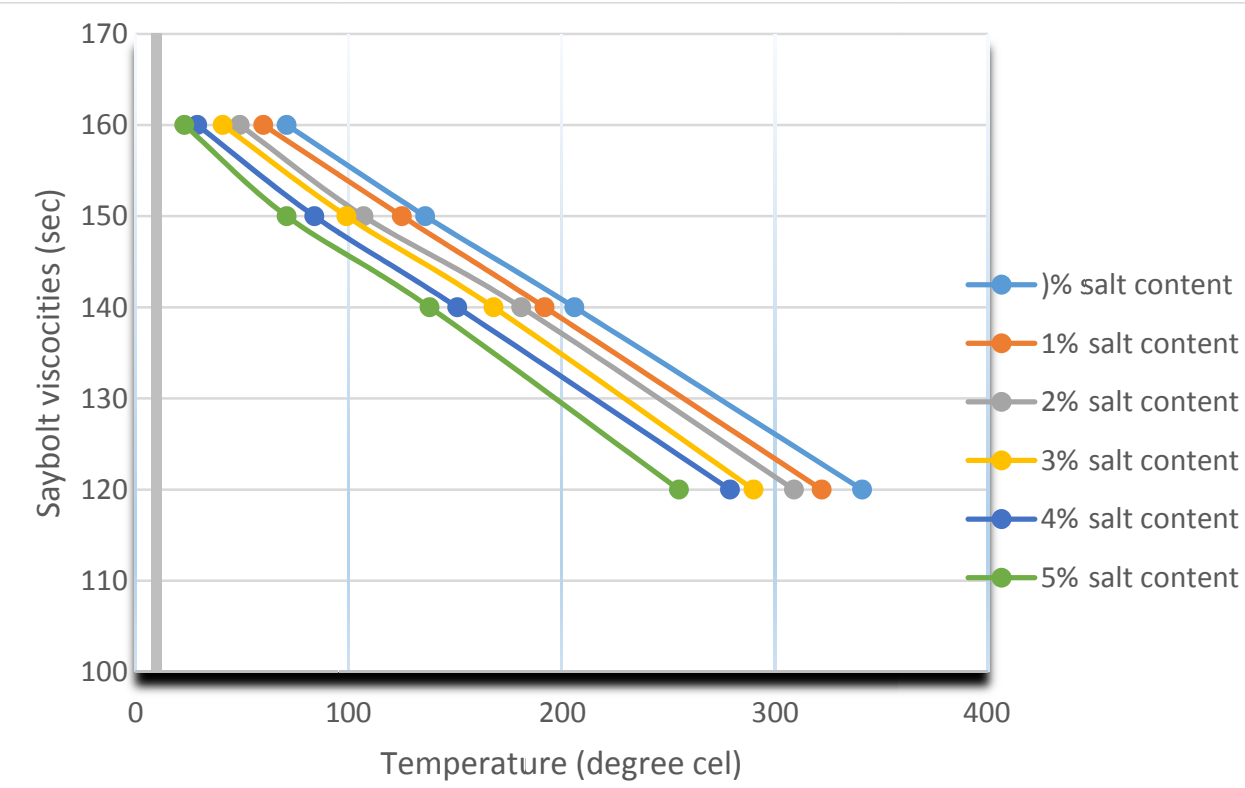

Fig. 10 Result of saybolt viscosities test of Bitumen.

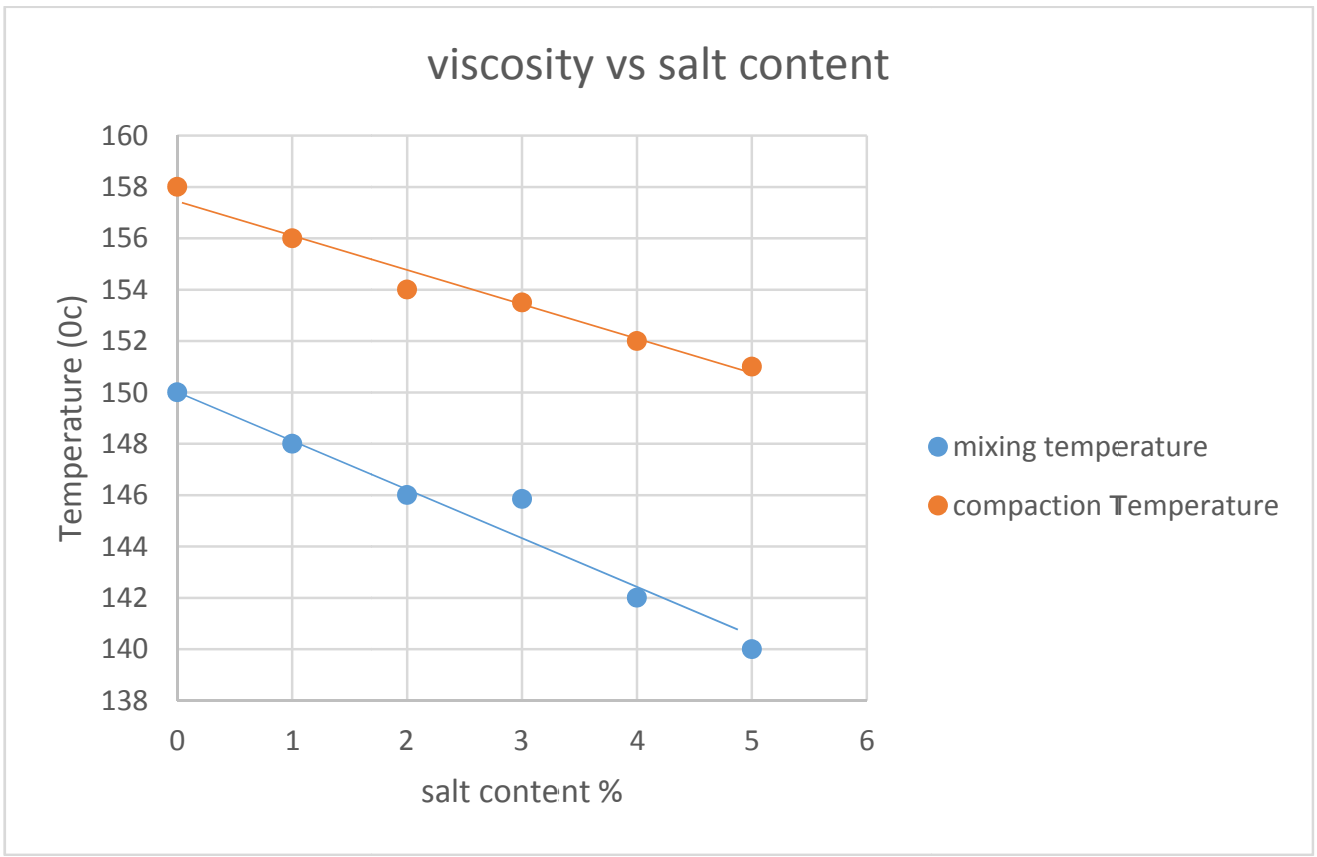

Fig. 11 Viscosity of mixing and compaction temperature with salt content in binder bituminous mix. 


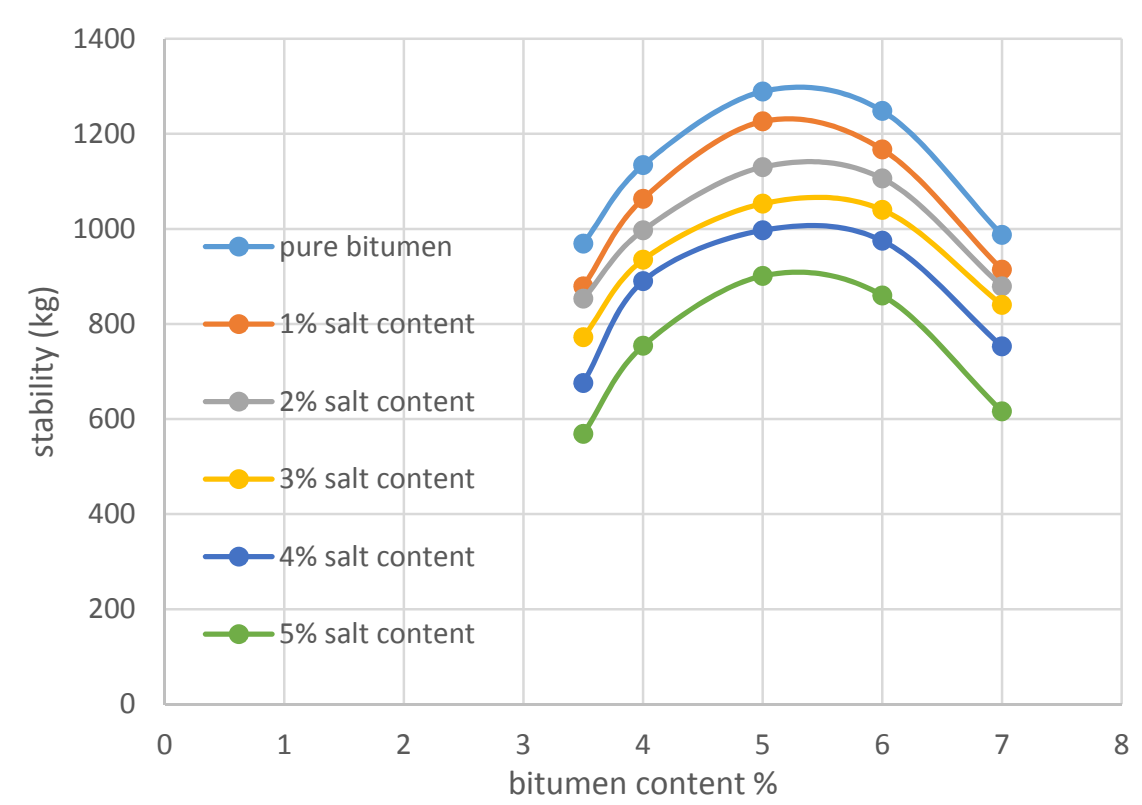

Fig. 12 Variation of stability value with respect to bitumen content.

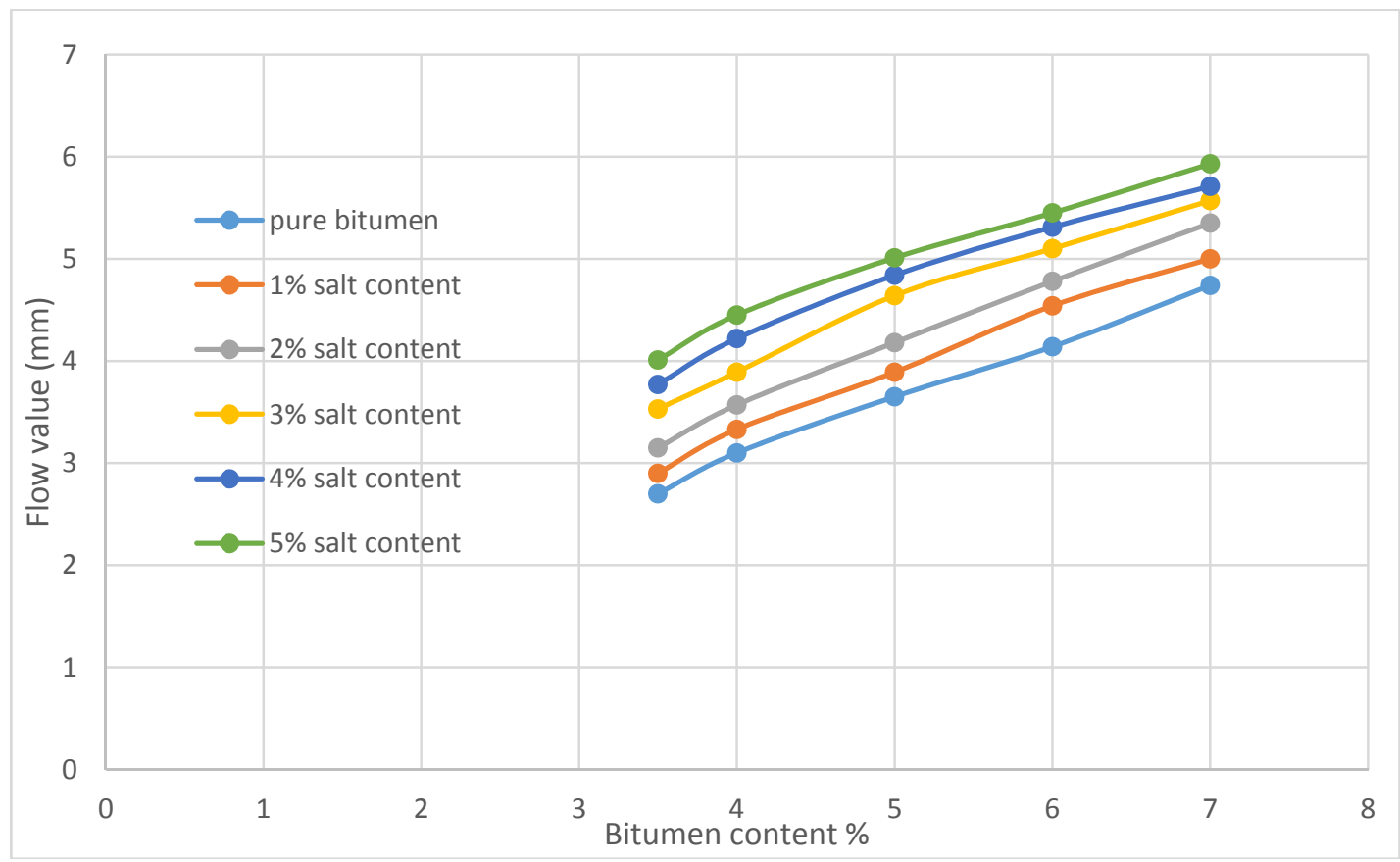

Fig. 13 Variation of flow value with respect to bitumen content percentage. 


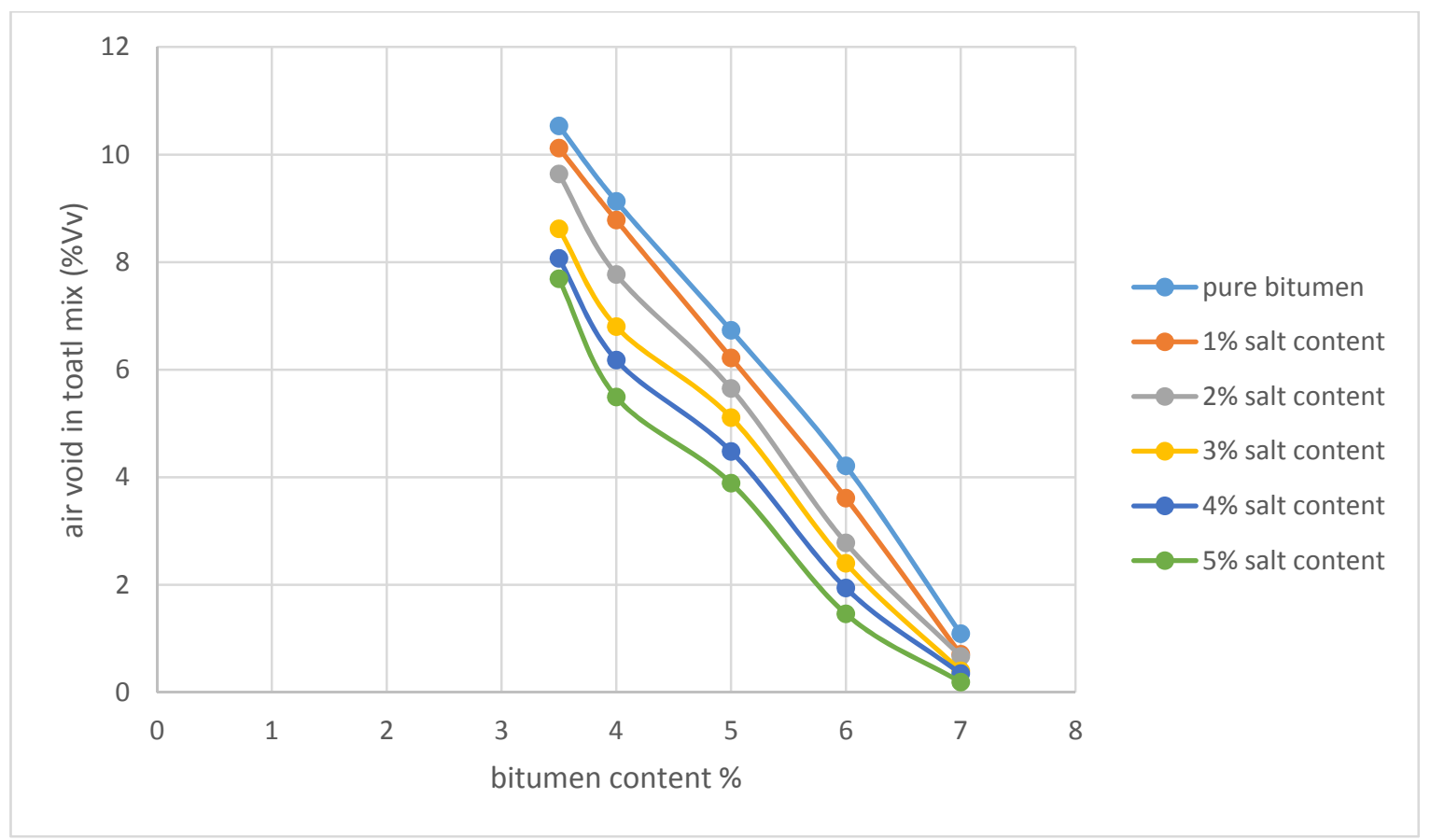

Fig. 14 Variation of percentage of total mix ( Vv) with respect to bitumen content percentage.

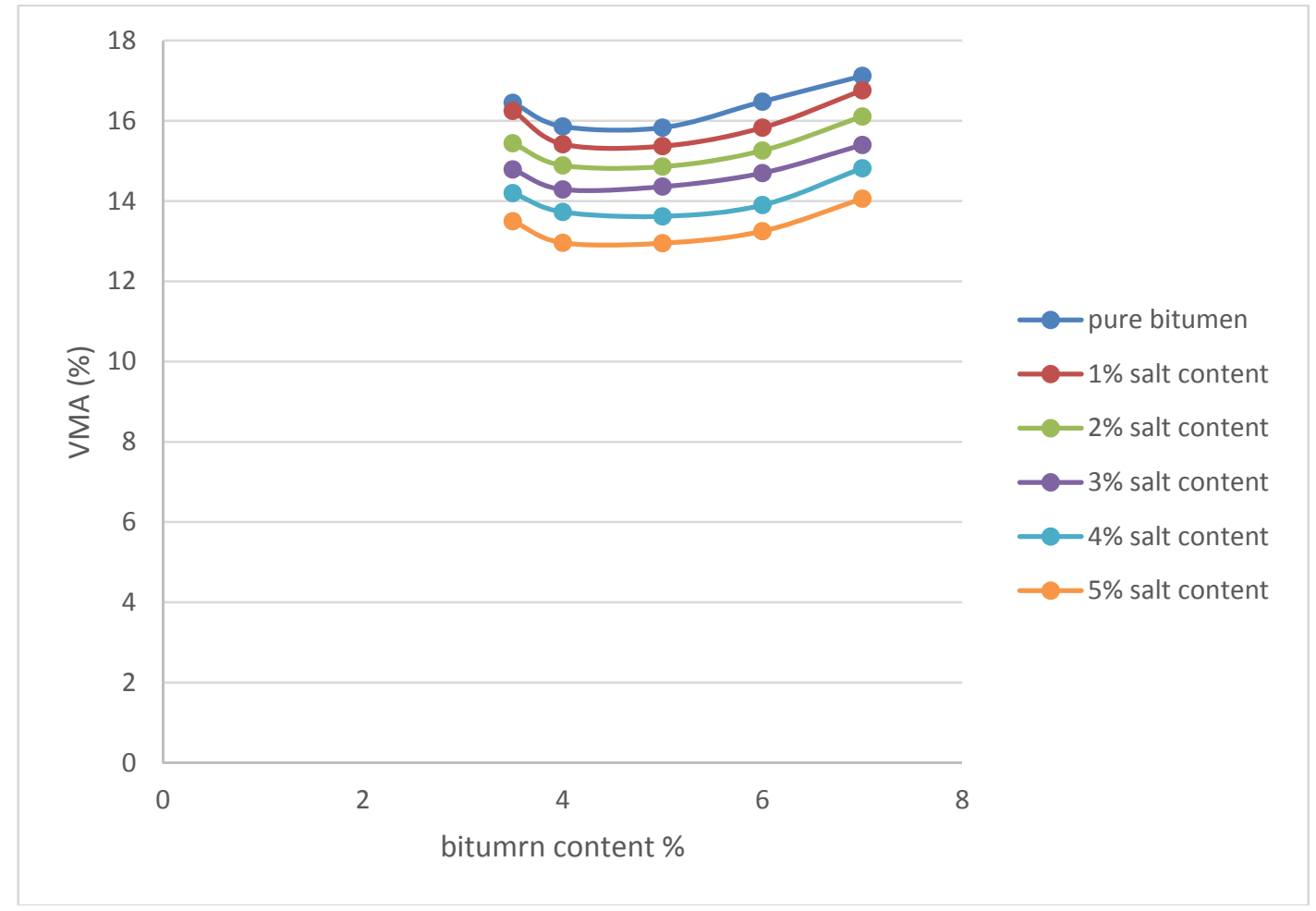

Fig. 15 Variation of percentage void of mineral aggregate with respect to bitumen content. 